the surgeon what they expect you to do before the start of the operation.

32. Revise the management of postpartum haemorrhage before starting.

33. Do not discharge pregnant women with abdominal pain or PV bleeding without consulting a senior colleague first.

34. Remember that pregnancy is not an illness.

35. When faced with an obstetric emergency, call for help from the obstetric, anaesthetic, and paediatric teams and then remember Airway, Breathing and Circulation (ABC).

36. During the placement become familiar with normal vaginal deliveries.

37. Become confident at examining a pregnant woman's abdomen during your placement.

38. Never prescribe NSAIDs to pregnant women.

39. If unsure always check what you are prescribing is safe for pregnant/breastfeeding women as appropriate.

40. Consider sitting the Diploma of the Royal College of Obstetricians and Gynaecologists (DRCOG) during your placement as this will be the easiest time to sit it.

\section{Alexander Goodman and Matthew Burkes}

DOI: 10.3399/bjgp11X567324

\title{
What is the collective noun for a group of patients?
}

Every weekday lunchtime I have a scheduled telephone surgery. It sends the practice's phone bill skywards, but we accept most such calls nowadays are to mobiles as people are busy (or like to appear busy!). Despite this, up to a third of these consultations fail to take place. This is partly because one of our receptionists has a rather annoying habit of being one random digit out, in the given eleven. Other reasons we're told, include: batteries running low; bosses demanding they be switched off; or because our rolling southern Scottish landscape still has many 'blind spots.'

I therefore find myself each day listening to a robot curtly telling me to leave a message or to a pleasant local accent asking me to accept one's apologies. My 'message' I recently noticed is a little odd, suggesting I indeed called at the arranged time but as I have a 'wall of patients' for the rest of the afternoon it is unlikely I will be able to call back. Quite how I arrived at such a contrived construction cliché I have no idea, but it caused me to ponder on my reasoning and imagery. A wall suggests a homogenous, perhaps insurmountable, and featureless barrier to freedom. Many surgeries could legitimately be described thus but if a wall is an unsatisfactory term, what is the correct collective noun for a group of patients? A coffee-break search of the literature did not yield any accepted terms or any results at all so I offer you now some plausible possibilities.

An Expectation of patients. Increasingly, these expectations are unrealistically high and we are therefore bound to disappoint. Some chest physicians and other doctors may prefer the more offensive Expectoration of patients!

A Murder of patients. Stealing the term for a group of crows but may be more apposite for the unfortunate victims of Drs. Shipman and Bodkin Adams.

A Gaggle of patients. Another ornithological term but a Google would serve to remind us how well read our patients now consider themselves to be.

A Profit of patients might be how less scrupulous private practitioners view their clientele.

A Hospital of patients is, ironically, a bit sterile and as the tendency seems to be to empty beds as quickly as possible, a Discharge of patients would seem fitting. A Community of patients is worthy of consideration too as, by extrapolation, that is where all patients will soon reside. I also like an Infirmity of patients but this might be considered a little too submissive and lacking in patient empowerment (whatever that actually is!)

An Intolerance of patients nicely covers both the increasing demands and the plethora of allergies we now face in general practice. (Why not a Plethora: of classical origin and suitably ambiguous to lay personnel?)

A Concern and a Complaint of patients similarly have dual connotations; both negative and positive.

Patients and our relationships with them are ever-changing and I think a collective noun illustrating such fluidity would suit. Some practitioners may be fortunate enough to have a steady Trickle of patients on whom they can devote their attentions and skills but most are rather overwhelmed by a Tidal Wave or Deluge. But the term which for me best encapsulates the nature of my work, always too busy and struggling to stay afloat, is a Torrent of patients. It might be best that I don't use this phrase on the phone though!

\section{David Carvel}

DOI: 10.3399/bjgp11X567333 